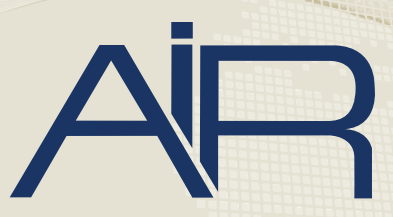

Association for Institutional Research

\title{
FROM DATA CRISIS TO DATA-CENTRIC
}

\section{Rebekah Anderson Nichole Rip}

\section{About the Authors \\ Rebekah Anderson is chief information officer at University of Western \\ States. Nichole Rip is data architect at University of Western States.}

\section{Abstract}

The main purpose of institutional research (IR) is to provide objective, systematic, and thorough data that support an institution's enrollment goals, planning, policy formation, and decision making. Traditionally, institutions gathered data on their activities, students and staff, programs, management, and operations. University staff then analyzed and interpreted those data to inform decision making down the road. In the case of our institution, there was only limited and non-cohesive data when a reorganization of the personnel and department structure occurred. The purpose of this paper is to explain the strategies and institutional shift University of Western States (UWS) used to facilitate strategic and datadriven decision making; how UWS improved the data, technology operations, and data management to cultivate an environment of data stewards; and how UWS turned these data into valuable information to use for strategic decision support.
Keywords: Institutional research, data governance, infrastructure, alignment, automation, executive buy-in, trust, business analysts, database, data management, information systems

\section{Background}

Once known as Western States Chiropractic College, University of Western States (UWS) is a small, private, nonprofit institution located in the Pacific Northwest. In order to respond to increasing needs for integrated health-care education in the region, in 2010 UWS added the College of Graduate Studies, which offers graduate degrees in human nutrition and functional medicine, in exercise and sport science, in diagnostic imaging and residency, and in other subjects, in addition to the doctorate degree offered by the College of Chiropractic. This change supported the UWS's mission and brought greater depth and diversity to its integrated focus on health care.

In 2010 UWS's regional accreditor, Northwest Commission of Colleges and Universities (NWCCU), recommended that the university improve its data collection and assessment efforts. During its mid-cycle visit in 2012, NWCCU found that UWS had made little progress in these efforts and asked the university to resolve the problem before its end-of-cycle review that was scheduled for 2015. In response, the university hired institutional research (IR) personnel who could adequately address its data-related concerns.

By 2015 several different administrative departments were dictating to the Office of Information Technology which projects were of highest priority, thus helping to create an environment of chaos and uncertainty. Ongoing projects were abandoned to start new ones, projects were rarely completed, and the data were siloed. Causing additional issues, department leaders were buying software they thought was most appropriate for their needs without information technology (IT) knowledge, involvement, or consent. These multiple softwares increased the already chaotic environment and led to the creation of a number of shadow systems. Each department was in its own silo and, although some had the same needs, each department had different products and/or licensing agreements, causing inefficiency and wasteful redundancy.

One of the first priorities for the newly hired IR specialist was to find information in the various data silos, which proved to be a difficult and labor-intensive task. Often the data were not in a central location, if the 
specialist was able to find them at all. Even when the specialist found the data, there were no obvious or simple ways to link records within and between the various information systems; no one had given thought to the need to get data out of the disparate systems. This situation not only negatively impacted the IR specialist's ability to build statistics about UWS, but also impeded the process of providing operational and recurring information needs.

There was no quick fix for these major issues. UWS began a long journey of revamping the systems, data, and people in order to implement longterm fixes that set the university in motion for a multiple-year plan of leadership changes, reorganization of the personnel structure, and implementation of data governance and project management frameworks.

\section{METHODOLOGY}

\section{Development of a Problem Statement}

Once the IR specialist understood the current state of UWS, the specialist needed to find colleagues at various levels, skills, and experience at the institution who shared a common understanding of the university's challenges and were willing to help lead the changes. With this in mind, the IR specialist teamed up with the database administrator to work on getting the vice president of institutional effectiveness to understand the situation. The specialist did this by explaining the challenges of providing IR without consistent practices. Eventually, the vice president of institutional effectiveness showed a solid understanding of these concepts and created a visual process diagram that was used to inform the rest of UWS's cabinet of the IR activities at the university. It was also important to determine the strengths of the partners and to divide up responsibilities accordingly. In this case, the IR specialist had a fresh perspective of the issues, but also needed allies from the executive leadership team and IT Department. This group ensured they all had the same understanding of the problem before taking the next steps.

A problem statement (figure 1) was created in order to verify that all three in this group were explaining the issues consistently and accurately. The problem statement noted that the university was in a data quality and availability crisis, which hindered its ability to provide demonstrable outcomes that showed mission and core theme fulfillment (a NWCCU requirement).The two main problems could be summarized by combining several overarching issues: the lack of centralized data, the lack of a project management framework, the lack of resources to provide effective data management, and the lack of integration and centralization of enterprise systems.

After creating the problem statement, the group developed and thoroughly communicated a reorganization plan. Processes were created and implemented to create the frameworks needed for project and data management in a collaborative, systematic, and prioritized way.

Stakeholders were educated throughout this process in a series of meetings, committees, and ad hoc conversations. The restructured team provided system and data validation and monitoring to ensure continued success, as well as customized and automated reporting to ensure robust decision support.

\section{Development and Communication of Reorganization Plan}

Because of concerns over personnel, the IR group created a reorganization plan (figure 2) in order to move forward on much-needed improvements. At the same time, various IR personnel kept the executive level, as well as stakeholders at the tactical level, informed to attempt to get buy-in and understanding from all levels of the organization. The data management issues identified in the problem statement were also a recurring discussion at the data integrity team meetings to keep the data issues at the top of the list of improvement projects.

The initial proposed reorganization (figure 2) consisted mainly of separating the data management personnel from those working on the IT infrastructure and help desk and infusing the data management side with resources to create a more efficient operating model. It was important to understand that buy-in was needed at all levels to ensure the success of these major changes. The method used was therefore a balanced mix of offering education around the benefits of these changes and evidence 


\section{UWS Data Quality and Availability Problem Statement}

December 22, 2015

As amplified in the December 2015 NWCCU “Peer Evaluation Report," UWS is in a data quality and availability crisis, which inhibits the institution's ability to demonstrate verifiable outcomes related to core themes and mission fulfillment. The crisis stems from

1. absence of a supported, centralized data and project management framework and qualified personnel to coordinate and manage the institution's data enterprise; and

2. misaligned and/or unintegrated enterprise application system features and unintegrated or loosely integrated enterprise systems.

These issues are interrelated and, when resolved, will allow for the natural development and incorporation of an institutional data platform. The value of such a data platform is to build a shared understanding and high level of confidence in data related to admissions, enrollments, curriculum and student outcomes, fiscal services, student services, auxiliary services, health services, accreditation, and federal compliance.

\section{Next Steps}

Identify and establish a dedicated/focused data enterprise management structure and personnel to accomplish the following characteristics and outcomes:

- Streamlined and effective business processes across the university that result in available, accurate, and meaningful data to inform decisions and effective planning that bring about achievement of the UWS mission, goals, and strategies (continuous improvement and institutional effectiveness).

- Alignment of software system features and functionality that support established business processes and data generation across the university.

- Controlled, vetted, and integrated software system purchasing procedure and implementation (project management) on manageable timelines.

- Systematic assessment of student learning outcomes and program evaluation.

- Effective, efficient, accurate data reporting and data applications utilization experience for employees.

- Holistic, uniform, standard pathways of communication and organization for report development and customization, system feature requests and prioritization, issue reporting and solution development and implementation on manageable timelines, data analytics (aka reports and dash boarding) requests and prioritization to meet institutional, research / effectiveness requirements, data enterprise alignment and advocacy, and measured results.

Note: The IR specialist, IT representative, and vice president of institutional effectiveness collaborated to create the problem statement, which summarized the data quality and availability issues UWS was facing and allowed the three of them to separately educate various stakeholders of the university while remaining consistent with the message.

to prove to executives why they needed to support the changes.

The regional accreditation site visit discovered the same data issues that were already internally noted. UWS was unable to provide common key performance indicators toward its mission (e.g., how many alumni donated and referred students to the university, what our historic enrollment numbers were, and how many continuing education hours UWS provided). After several years of requesting that the institution improve its data management practices, UWS regional accreditation went on warning status - due to the state of the data 
Figure 2. Enterprise Data Management Structure

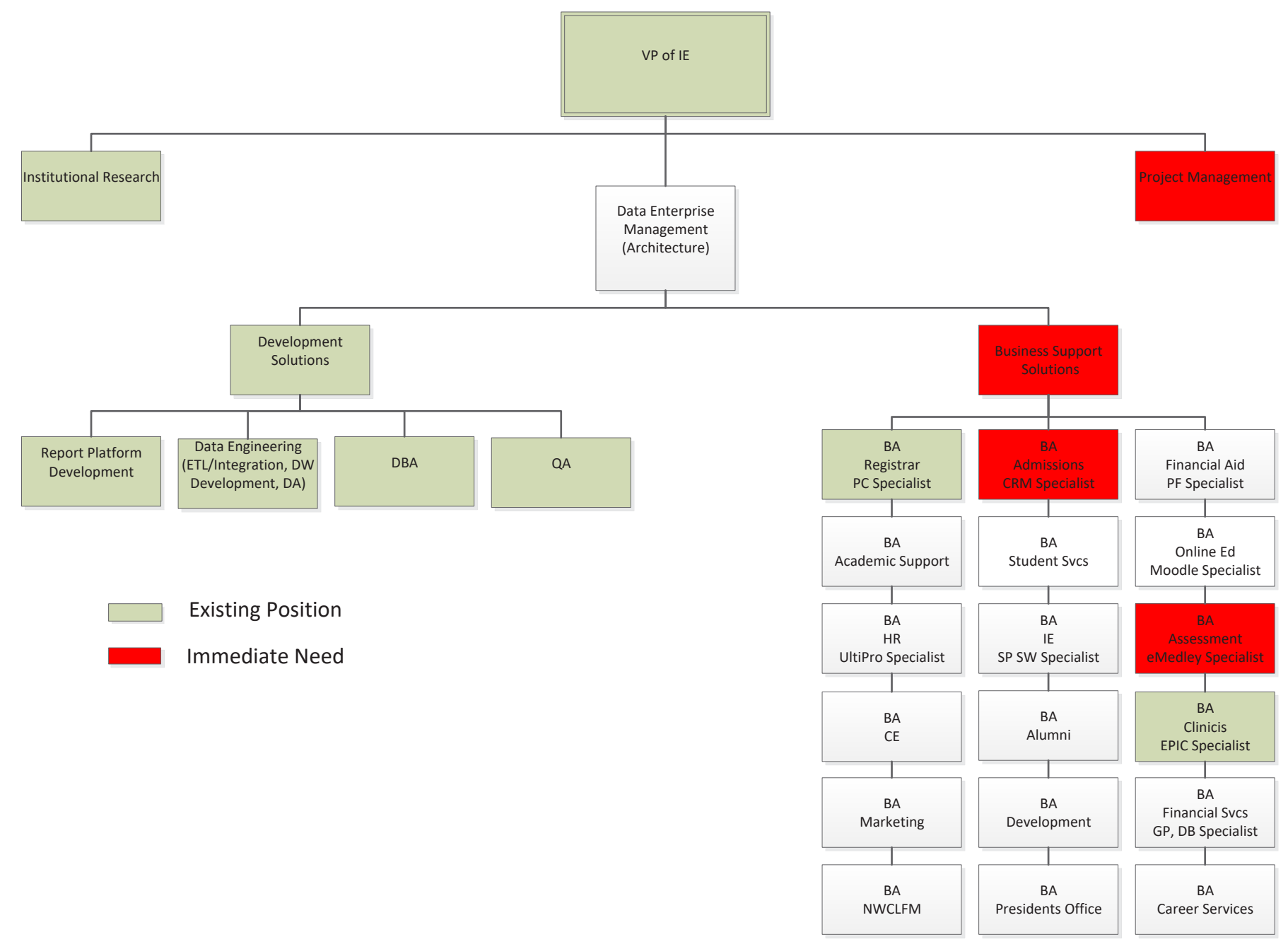

Note: Developing the enterprise data management structure assisted the vice president of institutional effectiveness with requesting additional personnel to improve data management.

and its lack of significant efforts toward improvement, and primarily due to the institution's lack of ability to make datadriven decisions.

\section{Development of Processes to Enable Systems and People to Work Together}

The institutional effectiveness reorganization included adding three additional personnel, two business analysts, and a project manager, as well as increasing the role of the database administrator role to include data architecture. Prior to the shift, the staff were maintaining current applications without business process support, and without integrating systems or improving the technology. Establishing these changes, the focus shifted to a more holistic solution frame of mind. Instead of only looking for a fix inside the existing noncustomized student information system (SIS), the analysts would now look at how the problems could be solved through a business process improvement, a system configuration modification, report, and/or system integration (figure 3). Although it would have been ideal for this group to be under a single leader within IT, UWS executives now recognized that data management 
could not be improved at this time without separating these groups and adjusting the current leadership.

The project management framework enabled the institutional effectiveness team to focus on important efforts through prioritization across the entire organization. Project management processes were put into place that allowed each department to monitor the status of its project. The project manager framework enabled institution-wide prioritization and transparency. Prior to this process, IT staff would start projects but then abandon them once something deemed more important came along. There was no evidence of any successfully completed projects prior to this shift. Although these processes were created and implemented in institutional effectiveness, they played little role in deciding which projects the staff were to work on. The IR team created an equitable structure that allowed all staff to suggest a project that was based on principles of need and on that project's benefit to the university. In addition, the institutional effectiveness personnel provided project proposals, charters, requirements documentation, and other important project documents to enable better understanding of the project's value before executive leadership decided on priority.

Around the same time in 2015 the executive leadership team underwent massive changes. Executives that once allowed loopholes in organizationwide prioritization departed and were replaced with an interconnected team

Figure 3. Issue Resolution Process

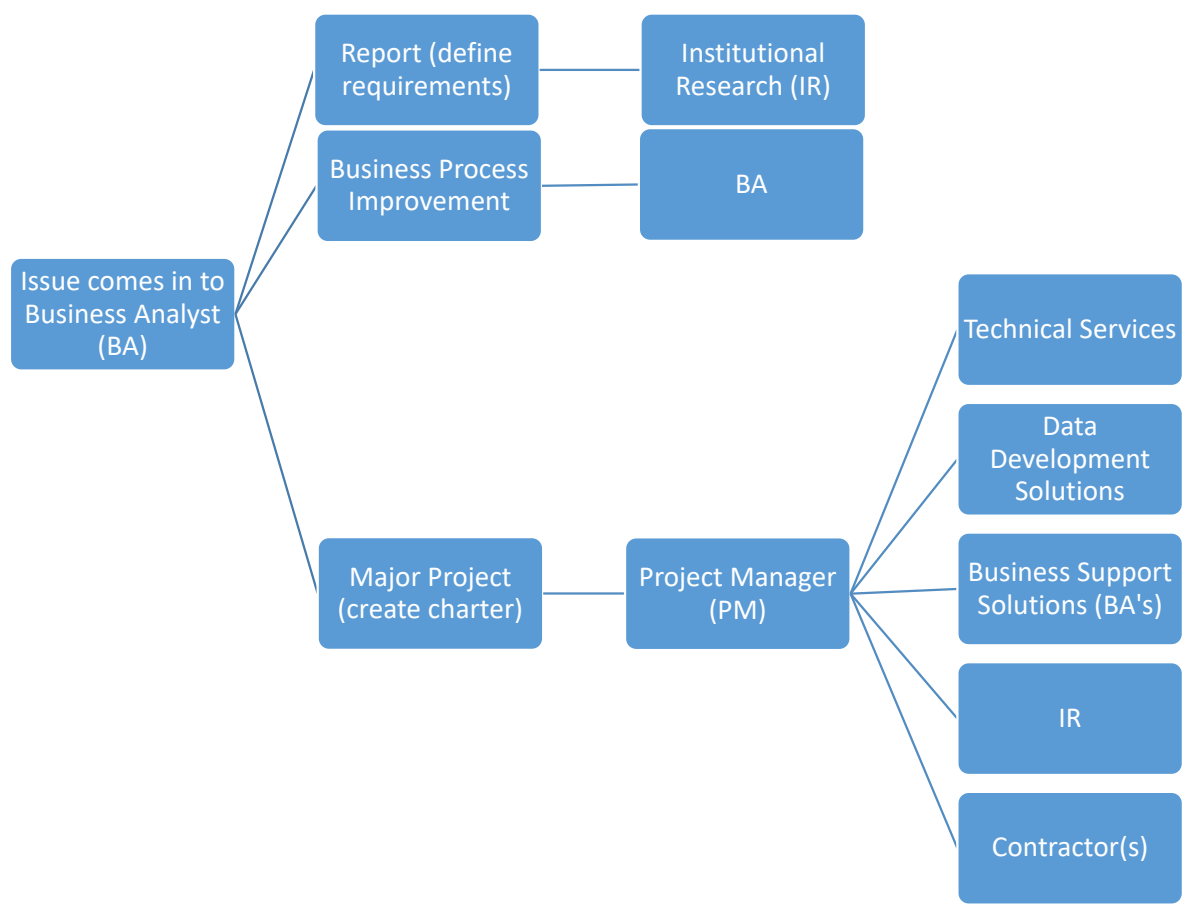

Note: The issue resolution process was created to show how issues would be resolved after the enterprise data management structure was implemented.

that allowed for transparent and fair processes. New leaders provided muchneeded cohesive vision, a clear sense of direction, and open communication; together they worked at providing a more positive environment.

Executives were educated about the need for systems integration, and why that integration needed to be prioritized as a critical requirement in the implementation of a customer relationship management system. This education allowed the team to prioritize its work and to focus on the important projects that in the past had been abandoned to make way for a new priority or emergency.

\section{Data Architect Role}

There have been many advancements to ease the burden of excessive resources dedicated to maintenance. Just a decade ago the amount of daily activities needed to keep systems afloat was a part-time job. Now, between informative monitoring alerts, cloud-based applications, and selfhealing systems, the time dedicated to maintenance has diminished. As a result, IT staff can now dedicate more effort to the development of programs that improve productivity and data quality, and can help UWS distinguish itself from competitor universities. While this is an exciting prospect, one of the challenges in this advancement is whether the university will be able to maintain overall enterprise system balance and prepare for growth. 
In order to capitalize on these

advancements, systems require handling in a more comprehensive capacity where modules, configurations, and data flows work in unison in an effort to reduce business processes and data redundancy. This directing of technical activities can be done through various roles but is best achieved through a central and senior technologist whose focus is more on systems design and less on people management. Since the notion of having access to and basing decisions on data was an accrediting imperative, UWS needed the skillset of a data architect.

Primarily, the data architect's focus is on business intelligence schema and system design, where the data architect works in concert with the institutional effectiveness team to maximize system resources and direct them toward a common goal of optimal data quality, retention, and speed of delivery. The data architect is constantly being educated on methodologies of systems and data maintenance in light of advancing technologies to plan for future needs. The main value of the data architect at UWS is to provide architectural diagrams of how technologies will be applied to solve various data needs. These diagrams serve to inform and document how to set up environments, configure the technologies, and foster an understanding of business process flow for the purposes of collaboration and improved end-user experience and productivity.

The data architect needs to maintain a certain level of awareness of errors in the system to direct solutions so the whole system is balanced and stabilized. Every configuration and every change within the system radiates an effect that is primarily experienced by the administrative staff. If the configurations are not streamlined, users become overworked due to lack of automation; if a change is made to the system that causes some type of breakage, users are unable to get their work done. Additionally, a poorly functioning administrative staff and ineffective technologies translates into negative student experiences that could result in loss of tuition, revenue, and reputation for the university. The data architect can serve to increase positive experiences by directing those activities that allow changes and growth to occur while maintaining balance.

\section{Reorganization}

As is true for most small institutions, while it can be challenging to understand the need for additional staff, actually finding the funds for these additional staff is an entirely different challenge. Once the executive leadership understood the dire nature of the data management deficiencies, they made decisions to find resources for the newly formed Institutional Effectiveness Department (later renamed Information Services Department). This new department resulted in the elimination of many executive-level positions, as well as positions that were not considered critical.

In addition, there was a shift in how resources were used. Prior to the redesign, academic leadership started new programs and specializations often, which inevitably spread resources thin. There was little understanding of the resources involved with planning these changes, which led to rushed implementations and further contributed to data quality issues. Under new leadership the failing academic programs were stopped and no new programs were initiated, which enabled existing resources to be concentrated on efforts to improve data management. This would eventually lead to betterinformed and better-supported academic program decisions.

There was also some significant attrition in the IT areas that allowed for the further reorganization. A chief information officer position was eventually created and tasked with overseeing and bringing the departments back together. The chief information officer was able to provide leadership for the technical services side of the house to evaluate and bring attention to its structure and internal processes, and to provide a stable infrastructure for all the work needed to be completed by institutional effectiveness, now renamed as information services. With information services and technical services back under the same leadership, both departments were able to create their own identities while working in unison to support and manage needs for technologies at the university.

With the addition of business analyst positions, the information services team was able to supply resources needed to gather business requirements and translate them into technical requirements. This assisted 
the bottlenecked data architect so he could more easily complete the much-needed development work, data cleanup, system customizations, custom integration, and much more (figure 3). The information services team was now able to complete projects started years prior to the organizational changes, projects that had persistently run into roadblocks with disorganization preventing the project completion. The analysts became the hub linking business leaders, subject matter experts, project managers, data architects, quality assurance, technical services, and more.

\section{EDUCATION OF AND COMMUNICATION TO STAKEHOLDERS}

Another benefit of the synergy of the information services team, as well as the increasing support of executive leadership, was that it provided education about and allowed focus on the need for clean data. Prior to the formation of the Information Services Department certain departments would refuse to enter data into the SIS because they claimed the system was not reliable. This mistrust resulted in dozens of separate spreadsheets tracking the same data, even within the same department. The analysts developed data stewards throughout the university to help manage the data in each department; these stewards ensured data that entered the systems were clean and consistently followed standards and guidelines. Now that the analysts were helping to improve processes and were working with departments regularly, the data architect was able to create muchneeded big-picture plans to ensure all aspects were moving in the right direction. The data integrity team had been disbanded during the more challenging times, so a new committee was thoughtfully and strategically formed.

\section{Formation of Data Governance Committee}

Once executives had bought into the concept of data stewards, the stage was set for the information services staff to further refine functionality in the data management process. Ideally, each department would follow its own standard administrative tasks in conjunction with and in the context of a comprehensive streamlined workflow that included pathways for task strategy, planning, and work distribution. Furthermore, with the information services group being so newly formed, it was a challenge for staff in that group to create their own internal processes, given the need to balance the immense number of requests against system breakages. The project management process provided the information services group with some meaningful direction, but day-today data system administration needed its own kind of direction. Since UWS was newly focused on data, the Data Governance Committee served as the agent for change in data management.

There was some initial legwork that needed to be completed before UWS could form the Data Governance Committee: information services staff needed to complete the data governance charter (figure 4), the data/ information governance framework (figure 5), the data governance process actors (figure 6), data governance process deliverables and metrics (figure 7), the data governance information flow (figure 8), and the quality of data chart from data dictionary guiding principles (figure 9). Specifically, the data governance charter (figure 4) followed a standard UWS governance and committee structure template and laid the foundation for a democratic process for structuring data and information. The data/information governance framework (figure 5) and related diagrams with each component of the framework broken down into further details (figures 6, 7, and 8) ensured the implementation of data standards through the appropriate channels, namely ensuring that data definitions and policies were implemented through technology. The quality of data chart from data dictionary guiding principles (figure 9) offered a beacon of inspiration and desired end goals that could be included in a change control form to ensure the solution met with the vision.

In addition to these elements, some environmental pieces of knowledge also played a part in determining data standards. The first element was a conceptual business architecture that included a representation of all the departments, their members, their functions, the systems they leverage, and the measures for their success. The second was a systems matrix that is an inventory of all the types of technology that engines UWS, from the SIS all the way down to Excel spreadsheets. The final element was to begin to populate 


\section{Data Governance Committee}

The Data Governance Committee facilitates the coordination of data-related priorities and activities among data producers, consumers, and stewards across the University. The primary purpose of the committee is to facilitate data-driven decision making through the collection of reliable and verifiable data and production of timely and accurate data reports. The committee is charged to:

- Contribute to the fulfillment of the Mission, Core Themes, and Core Theme objectives through the collection, dissemination, and use of reliable and verifiable data.

- Make collective recommendations to the Provost regarding changes procedures, processes, and systems to improve the collection and application of data.

- Create data entry guidelines for data producers, and a data element dictionary for consumers and stewards.

- Review criteria and compare to guidelines to ensure university data meets the requirements of being trustworthy, consistent, accurate, audited, regulated, and secured.

- Provide a forum for proposing and discussing definitions for terms and associated data elements.

- Facilitate initiatives to improve quality or availability of data, information security and data retention, and policies on business processes or system configurations to manage raw elements of information.

- Discuss supplementary matters that pertain to governing data, administrative processes and information delivery.

- Engage in feasibility analysis for data initiatives and overall data infrastructure. Propose project initiatives where applicable.

- Review and provide feedback on information research reports including meaning, format, centralization and automation of reports.

- Perform other functions as may be delegated to the Data Governance Committee.

$\begin{array}{ll}\text { Subgroups: } & \text { Application \& Integration User Groups, Reports \& Analytics User Group } \\ \text { Meeting Frequency: } & \text { Once per month } \\ \text { Committee Authority: } & \text { Recommend } \\ \text { Accountability: } & \text { Chairs } \rightarrow \text { Provost } \rightarrow \text { President }\end{array}$

The Data Governance Committee is comprised of members of the staff and administration, including:

\begin{tabular}{|l|l}
\hline Application Analyst, Power Campus & Director, Financial Aid \\
Business Analyst(s) & Director, Institutional Appraisal \& Accreditation (chair) \\
Controller & Executive Manager, Clinical Internship \\
Coordinator, Student Retention (Student Services) & Manager, Alumni Relations \\
Data Architect (vice chair) & Manager, Information Services \\
Director, Administrative Services & Provost/VP, University Affairs (LO) \\
Director, Admissions & Registrar \\
Director, Marketing \& Communications & \\
\hline
\end{tabular}

Note: The data governance charter was created to articulate the purpose of the committee, identify committee members, and provide accountability for the committee. 
Figure 5. Data/Information Governance Framework

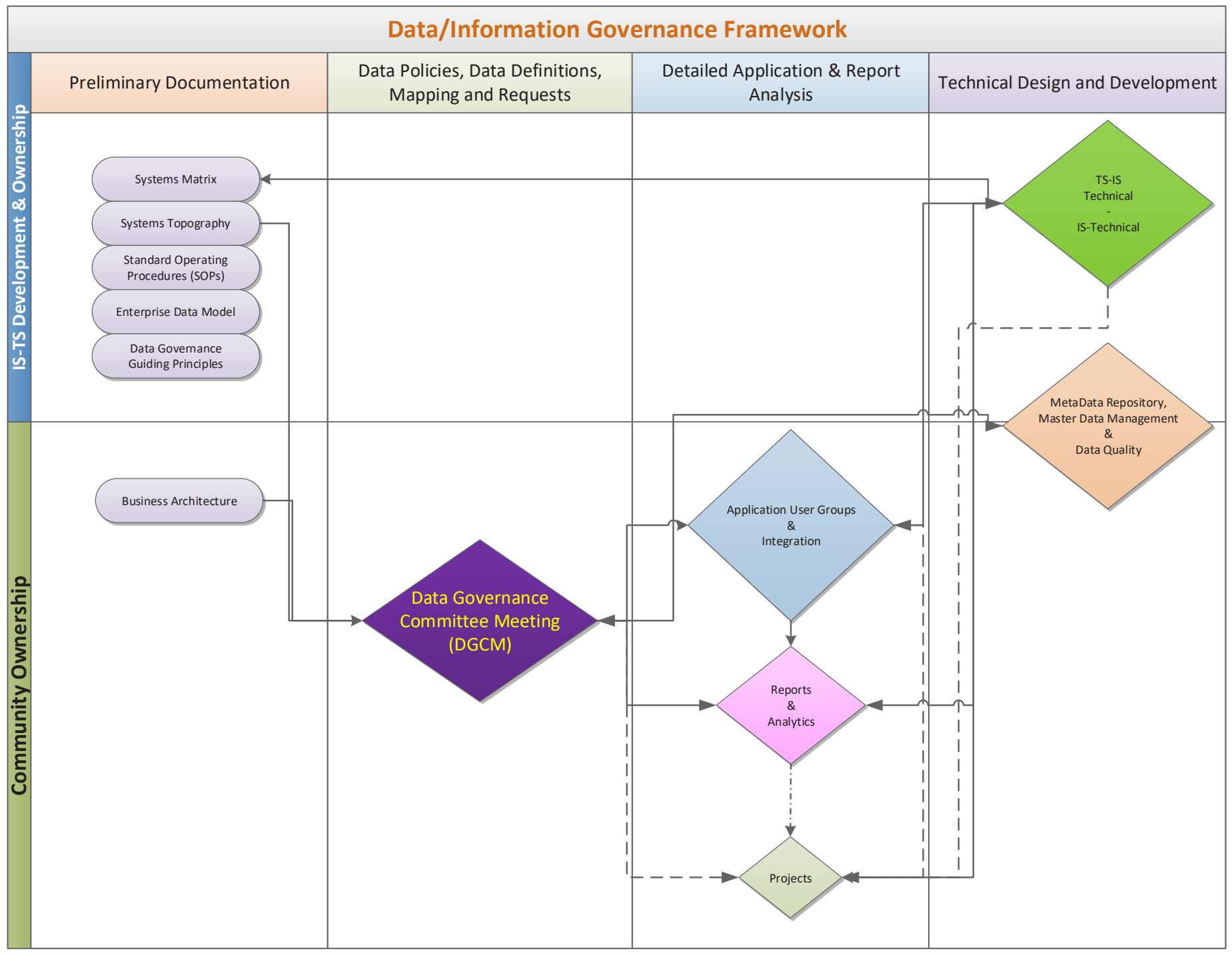

Note: The data/information governance framework was developed to show how the various elements flow to and from the Data Governance Committee meetings, and who owns the processes (left side shows this ownership). In addition, it shows how various documentation, policies, definitions, requests, analyses, and development relate to each other.

the data dictionary and business glossary, which are comprehensive lists of all reference data from the SIS and the main focal point for the Data Governance Committee's initial guidance.

\section{Creation of a Data Dictionary}

A data dictionary is another tool that is useful for educating users about the need for consistent and clean data. Although it can arguably be viewed simply as a list of field values and their definitions, a data dictionary is actually an efficient way of extracting and maintaining business and data rules. Example definitions in a data dictionary within the context of a university include values in the enrollment status field (enrolled, dismissed, leave of absence, never enrolled, summer 
Figure 6. Data Governance Process Actors

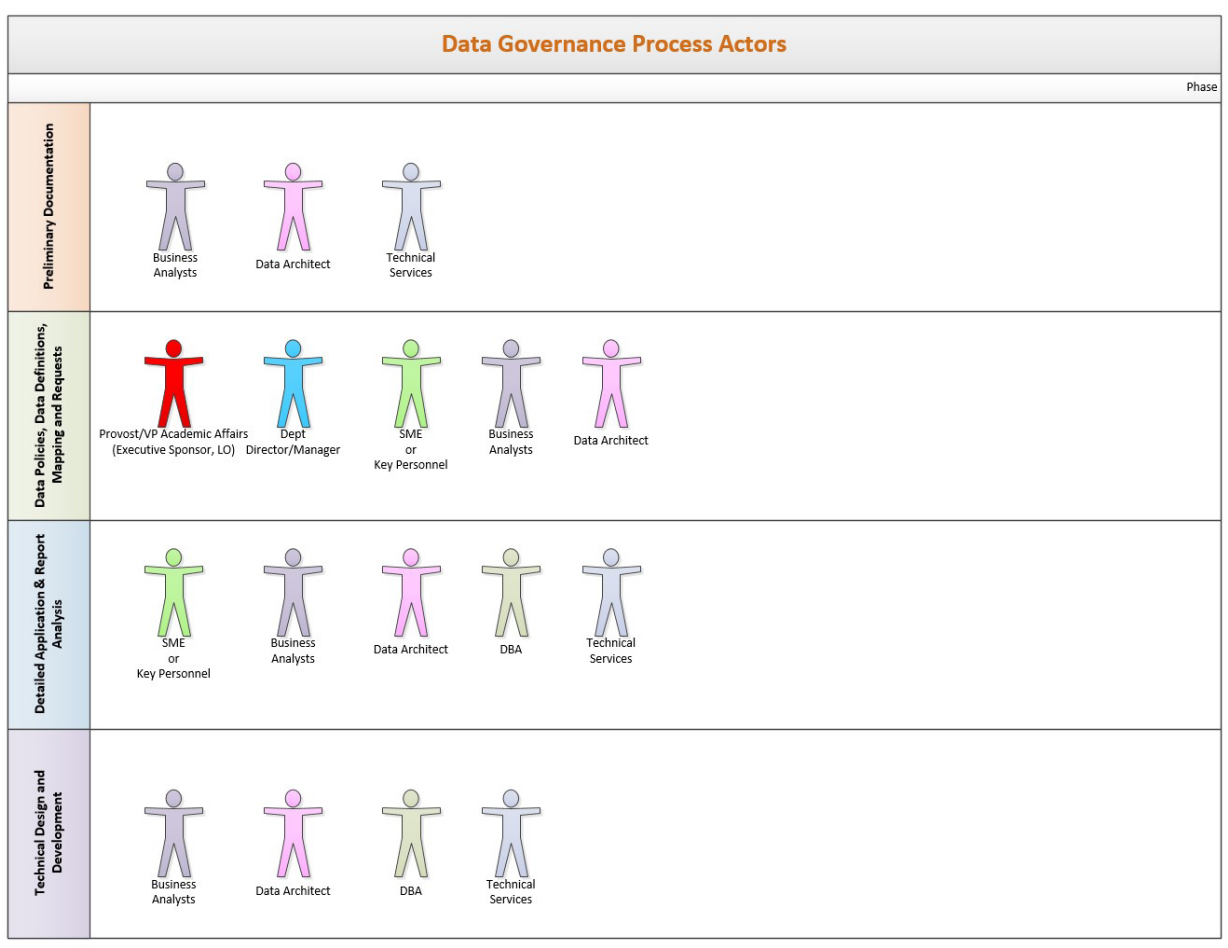

Note: The data governance process actors diagram expands on the data/information governance framework to add further details of which roles are involved with each section of the framework. It helps identify who is accountable for each area.

off, etc.) or course attendance status (added, dropped, withdrawn). The business glossary ties data dictionary definitions together into overarching themes and is a list of terms that describe the components of running an organization. Example terms that were included in the UWS business glossary are those associated with the student life cycle (inquiry, applicant, student, intern, alumnus, etc.) as well as the list of academic programs offered by UWS. The data dictionary (figure 10) and business glossary (figure 11) are tightly linked because both inform each other and create a map between administrative processes, the type of data collected, and how those data need to be entered. More importantly, the data dictionary and business glossary get administrators speaking the same language and help develop a common understanding of the overall picture of what each department is supposed to accomplish.

There are two main approaches to building this common understanding. The first is a bottom-up approach starting with a data dictionary whereby a comprehensive list of all the fields and their possible values is pulled from each database system using the database software-specific metadata tables. A committee discusses and defines each field and value one by one. In creating definitions this way, themes emerge that transform into terms that define larger processes as in a business glossary. This approach can be beneficial, particularly if there is contention between departments highlighted by poor data quality or enterprise systems, and subject matter experts are struggling to agree to the definition or to see their role in a larger context. The drawback of this approach is that the process will be extremely tedious and time consuming, and it likely will take longer for the organization to see the value.

The second approach is a top-down method starting with the business glossary; this is the approach UWS used. A committee agrees to a list of terms and then develops common definitions for those terms; in turn, the data architect can map these terms to system functionality. The definitions emerging from this method would align more tightly with the strategic plan, be more humanfocused, and would immediately provide administrators with a common language that they can begin using in daily interactions to raise the level of common understandings and to minimize common misunderstandings. This approach is beneficial if subject matter experts have positive relationships and data quality is reasonably good as a result of standard business practices.

This approach lends itself well to building a master data management system that ties common terms to field values in each of the systems and keeps them in sync. The main drawback of 
this approach is that if these definitions are not immediately followed up with discussions about the data elements inside the database systems (e.g., the data dictionary, mapping business glossary terms to field values) the value of this exercise is lost. If an institution experiences this it can become more complicated for information services staff members to explain the end product to users, which imposes a constraint on the system and is its own source of frustration for users.

\section{Encouragement of Campus- wide Engagement}

The Strategic Planning Steering

Committee was formed in the Spring of 2016. This committee provided another avenue to educate colleagues that represented various departments and levels about data governance and the need for a solid technology foundation. The outcome of socializing all the data technical issues at the institution resulted in three of the seven top goals focusing on data management (figure 12) and IT infrastructure. Simultaneous to working on the strategic plan, the university began modifying its core themes in conjunction with the new accreditation cycle.

The university updated its mission and core themes at the start of its FY17-FY23 accreditation cycle through a campus-wide engagement project.

The academic leadership teamed up with information services to create the Leaning in the Doorways Initiative, during which this academic leadership team interviewed nearly every university employee, asked them how they use data in their work, and
Figure 7. Data Governance Process Deliverables and Metrics

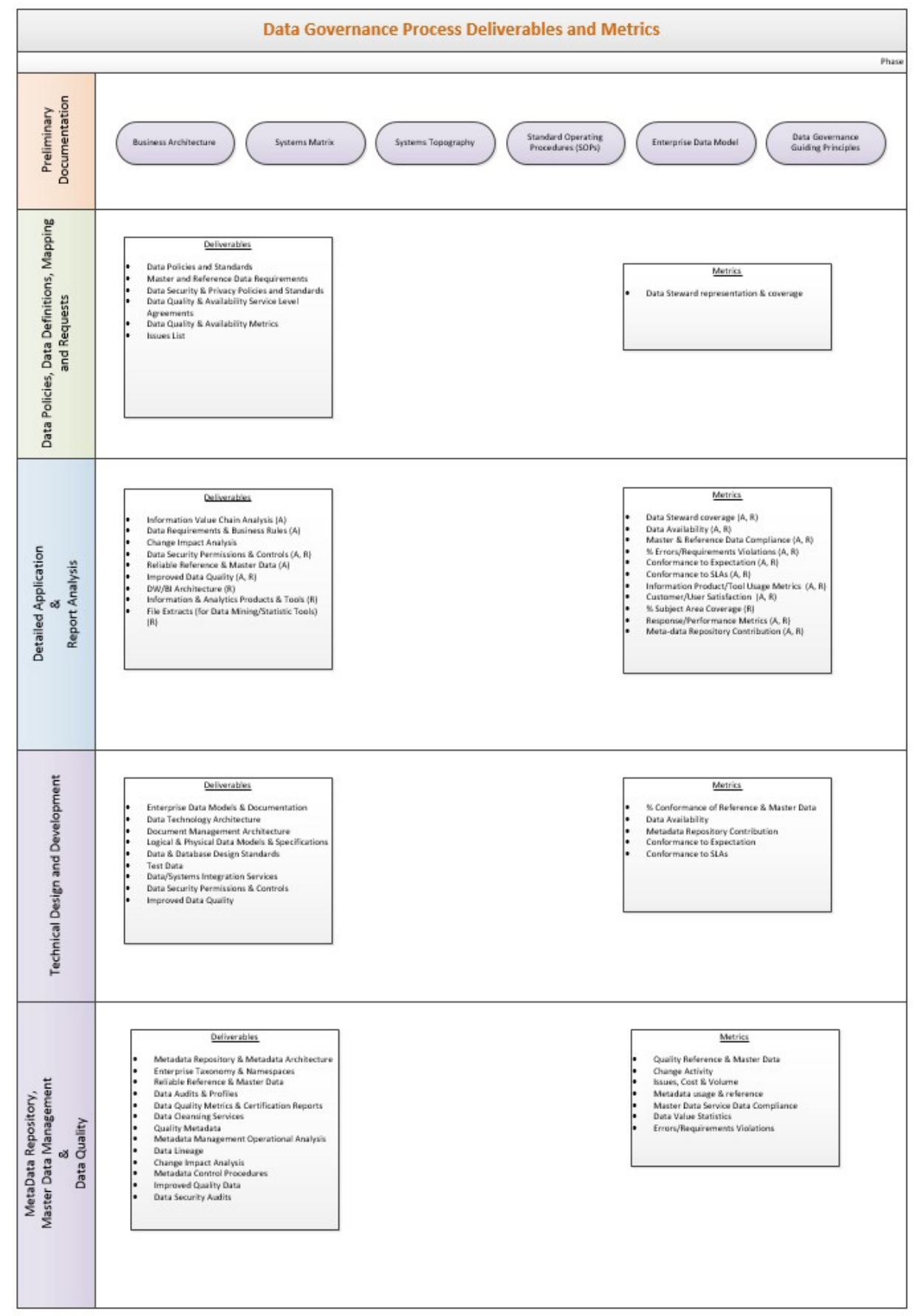

Note: The data governance process deliverables and metrics diagram expand on the data/ information governance framework to add further details of what will be created and provided in each area. 
Figure 8. Data Governance Information Flow

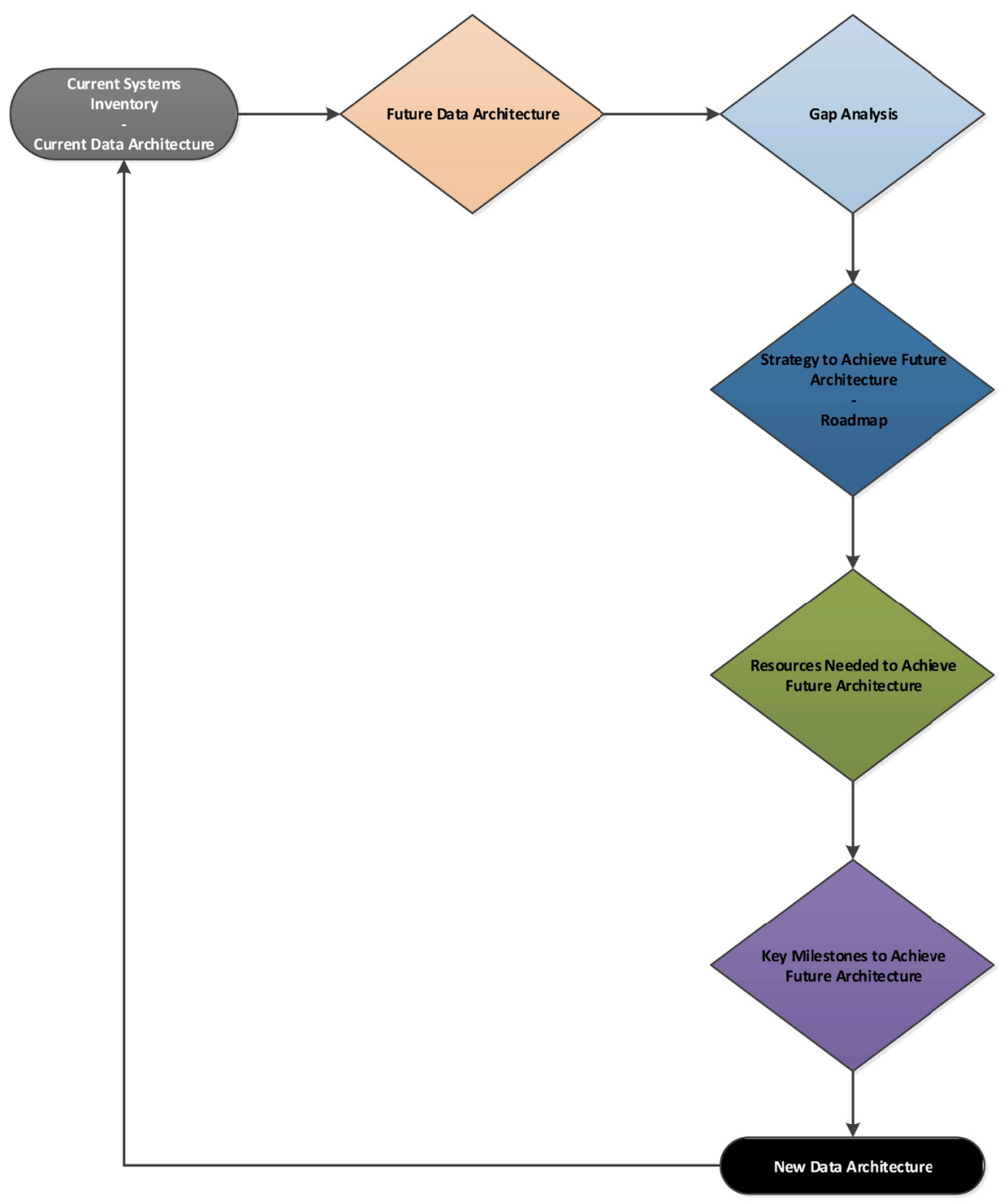

Note: The data governance information flow diagram expands on the data/information governance framework to add further details of how the deliverables are created and updated.

asked what they needed to fulfill their job duties. In addition to introducing employees to the importance of data, other personnel issues were positively affected by this initiative such as improved morale, with employees saying they felt like they were part of the solution as a result of this initiative.
This initiative helped produce not only an improved mission and vision, but also core theme measures that employees felt they were a part of. Employees began to think about how their positions contributed to the mission and believed that they might have valuable information to share. In the past it was difficult to get individual departments to contribute and to understand how their role fits into the big picture so this change was significant, and resulted in a more robust annual appraisal of the university, as well as a mission that was created by all. This experience also led to increased teamwork between academic affairs and the Office of Information Technology that has increased the fulfillment of data management improvement needs.

\section{User Community Group Meetings}

The user community meetings were another mechanism designed to ensure data definitions and standards are imbued into the system in the data governance framework. As terms are defined, business rules can be extracted, traced, and compiled into a coherent flow where system functionality is configured and data are entered according to the rules and standards. These definitions and standards also served as the foundation for increased automation, increased productivity, and more user experiences that were positive. Systemuser community group meetings help operationalize this process by collecting the subject matter experts to discuss various features, issues, bugs, or limitations with the systems. Also discussed in these meetings are workload and balancing tasks that staff negotiate so that the whole process and the life cycle are carried out more seamlessly. The users also work through a prioritization of building system improvements in conjunction with the 
Figure 9. Quality of Data Chart from Data Dictionary Guiding Principles

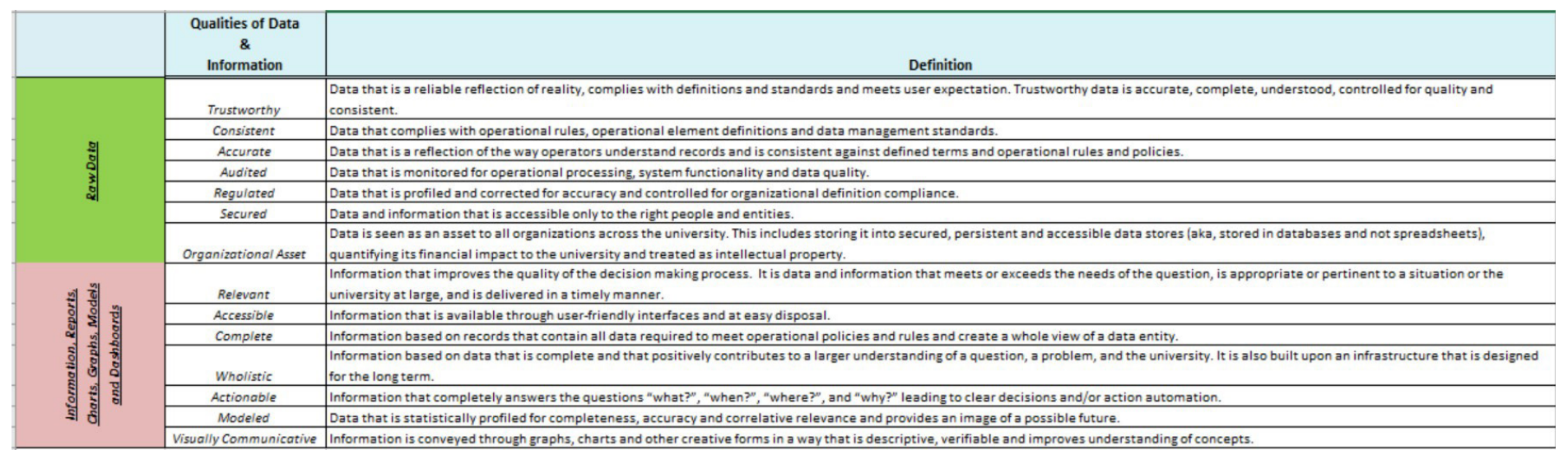

Note: The quality of data chart from data dictionary guiding principles provides a sample of what was created to show the target data quality features and what is meant by each of these qualities.

\section{Figure 10. Data Dictionary (Excerpts)}

\begin{tabular}{|c|c|c|c|c|c|c|}
\hline TableName & ColumnName & DataType & sNu & $\mathrm{dsPK}$ & AsFl & ColumnDescription \\
\hline ABT_ACCOUNTS & ACCOUNT_EMAIL & nvarchar(510) & No & No & No & Email account for user. \\
\hline ABT_ACCOUNTS & ACCOUNT_ID & nuarchar(16) & No & Yes & No & System-generated ID, independent of the user's people_code_id and their login ID. \\
\hline ABT_ACCOUNTS & COOKIE_ID & nuarchar(32) & Yes & No & No & Cookie ID for user. \\
\hline ABT_ACCOUNTS & CREATE_DATE & datetime & Yes & No & No & Row (record) create date. Updated automatically when the row is created. No keyboard access. \\
\hline ABT_ACCOUNTS & CREATE_OPID & nuarchar(16] & Yes & No & No & Row (record) create operator. Updated automatically when the row is created. No keyboard access. \\
\hline ABT_ACCOUNTS & CREATE_TERMIINAL & nuarchar(8) & Yes & No & No & Row (record) create terminal. Updated automatically when the row is created. No keyboard access. \\
\hline ABT_ACCOUNTS & CREATE_TIME & datetime & Yes & No & No & Row (record) create time. Updated automatically when the row is created. No keyboard access. \\
\hline ABT_ACCOUNTS & FULL_NAME & nuarchar(510) & No & No & No & Full name of person either built from name columns in PEOPLE table or user-entered for users that do not have a PCID \\
\hline ABT_ACCOUNTS & LAST_LOGON_DATE & datetime & Yes & No & No & Date user last logged onto the system. \\
\hline ABT_ACCOUNTS & LAST_LOGON_TIME & datetime & Yes & No & No & Time user last logged onto the system. \\
\hline ABT_ACCOUNTS & LOGGED_IN & nuarchar(2) & No & No & No & Account that is logged into PowerCampus. \\
\hline ABT_ACCOUNTS & LOGIN_ID & nvarchar(510) & No & No & No & Login ID for user. \\
\hline ABT_ACCOUNTS & ORG_CODE_ID & nuarchar(20) & Yes & No & No & Organization code ( $\mathrm{O})$ And ID \\
\hline ABT_ACCOUNTS & PASSWORD & nvarchar(510) & No & No & No & Password of user. \\
\hline ABT_ACCOUNTS & PEOPLE_CODE_ID & nuarchar(20) & Yes & No & No & People Code ID for user. \\
\hline ABT_ACCOUNTS & REVISION_DATE & datetime & Yes & No & No & Row (record) revision date. Updated automatically when the row is revised. No keyboard access. \\
\hline ABT_ACCOUNTS & REVISION_OPID & nuarchar(16) & Yes & No & No & Row (record) revision operator. Updated automatically when the row is revised. No keyboard access. \\
\hline ABT_ACCOUNTS & REVISION_TERMINAL & nvarchar(8) & Yes & No & No & Row (record) revision terminal. Updated automatioally when the row is revised. No keyboard acoess. \\
\hline ABT_ACCOUNTS & REVISION_TIME & datetime & Yes & No & No & Row (record) revision time. Updated automatically when the row is revised. No keyboard access. \\
\hline ABT_CODEREPORTCOLUMNS & COLUMN_DISPLAY & nuarchar(2) & No & No & No & Column display name. \\
\hline ABT_CODEREPORTCOLUMNS & COLUMN_DISPLAY_ORDER & int & No & No & No & Order within the code table that the non-standard columns are to be displayed. \\
\hline ABT_CODEREPORTCOLUMNS & COLUMN_NAME & nvarchar(70) & No & Yes & No & Name of column. \\
\hline ABT_CODEREPORTCOLUMNS & TABLE_NAME & nvarchar(70) & No & Yes & No & Name of table. \\
\hline ABT_COMPOBJECTS & ABT_JOIN & nuarchar(2) & No & No & No & Alw ays an asterisk"'. \\
\hline ABT_COMPOBJECTS & COMPONENT_TYPE & nvarchar(20) & No & Yes & No & Examples are: WEB system, VB system, etc. \\
\hline ABT_COMPOBJJECTS & CREATE_DATE & datetime & No & No & No & Row (record) create date. Updated automatically when the row is created. No keyboard access. \\
\hline
\end{tabular}

Note: The excerpts from the data dictionary provides a sample of items in the data dictionary, with details of which source table it is from, the column name, data type, whether it is a required field, a primary or foreign key, and the description.

analysts. With users understanding their role in a larger process and system configured to improve their productivity, they begin to increase their trust in the system and the information it provides.
In conjunction with system user group meetings were reporting and analytics user group meetings. The best approach for UWS to enable good information quality and to enhance interdepartmental communications was to build a centralized data repository where users can get the clean, accurate, and transformed data they need for their analyses. This made the reporting and analytics meetings even more important because those meetings are the forum for information stakeholders to discuss whether a 
Figure 11. Business Glossary (Excerpts)

\begin{tabular}{|c|c|c|c|c|c|}
\hline PowerCampus Program Code & Official Program Name & Campus Offering this Program & CIP Code & CreditLoadFullMax & CreditLoadFullMin \\
\hline DOC-EdD-SPSY & Doctorate of Education in Sport and Performance Psychology & Online & 31.0508 & 100.00 & 9.00 \\
\hline GR-CERT-NUTRIT & Graduate Certificate in Human Nutrition and Functional Medicine & Online & 51.3102 & 100.00 & 9.00 \\
\hline GR-CERT-POSLD & Graduate Certificate in Positive Leadership and Administration & Online & 31.0508 & 100.00 & 9.00 \\
\hline GR-CERT-SPTNUT & Graduate Certificate in Sports Nutrition & Online & 31.0508 & 100.00 & 9.00 \\
\hline GR-CERT-SPTPSY & Graduate Certificate in Applied Sport Psychology & Online & 31.0508 & 100.00 & 9.00 \\
\hline GR-MS-MDI & Graduate Master of Science in Diagnostic Imaging & Online & 60.0411 & 100.00 & 9.00 \\
\hline GR-MS-NUTRIT & Graduate Master of Science in Human Nutrition and Functional Medicine & Online & 51.3102 & 100.00 & 9.00 \\
\hline GR-MS-SPSY & Graduate Master of Science in Sport and Performance Psychology & Online & 31.0508 & 100.00 & 9.00 \\
\hline GR-MS-SPTMED & Graduate Master of Science in Sports Medicine & Online & 31.0508 & 100.00 & 9.00 \\
\hline GR-CONC-HLTHWL & Graduate Concentration in Health and Wellness & Online & 51.0001 & 0.00 & 0.00 \\
\hline GR-CONC-NUTR & Graduate Concentration in Nutrition & Online & 51.3102 & 0.00 & 0.00 \\
\hline GR-CONC-POSCOA & Graduate Concentration in Positive Coaching & Online & 31.0501 & 0.00 & 0.00 \\
\hline GR-CONC-SAA & Graduate Concentration in Sports and Athletic Administration & Online & 31.0504 & 0.00 & 0.00 \\
\hline PROF-DC-CHIRO & Doctor of Chiropractic & Portland Campus & 51.0101 & 100.00 & 9.00 \\
\hline UG-BS-HUMBIO & Bachelor of Science in Human Biology & Portland Campus & 26.9999 & 100.00 & 12.00 \\
\hline
\end{tabular}

Note: The excerpts from the business glossary provides a sample of items in the business glossary, with details of the SIS program code, the official academic program name, if it is online or on campus, the classification of instructional programs (CIP) code, and minimum and maximum credits associated.

Figure 12. Data Management Strategic Plan Goal

\section{Goal 1: Enhance our ability to purposely collect and use data}

\section{Objectives}

1.1. $95 \%$ of employee understand how to collect, use, and access data to inform decisions

1.2. Establish a data governance structure to improve data integrity by 2019

Implement a business intelligence

1.3. framework to optimize data-driven decisionmaking by 2020

\section{Initiatives}

1.1.1. Educate and train departments on the collection, use, and access of data 1.1.2. Conduct a data audit and gap analysis

1.2.1. Create data governance committee and subcommittees comprised of key stakeholders

1.2.2. Develop and implement guiding principles for data governance

1.2.3. Create and implement a data dictionary

1.3.1. Develop and implement a framework to support ongoing data-driven decision making 1.3.2. Improve and implement data analytics and reporting capabilities

Note: The data management strategic plan goal provides a sample of one of the three strategic plan goals that emphasize the need to improve data management and underlying technology infrastructure, and also provides details on the objectives and initiatives related to the goal of enhancing the university's ability to purposely collect and use data.

report or available data pool meets the definitions, to discuss their information needs, or to discuss how it reflects their sense of accuracy or validity. These weekly meetings can allow stakeholders to discuss the implications of any findings, and will provide the platform for machine learning and correlative analysis in the future.

Both user groups are supported by a more behind-the-scenes set of meetings solely involving the two houses of the IT Department. These meetings serve to delve into the bowels of the system for issue resolution of and direction for capacity and technology planning. Actions taken at this level will require their own internal set of policies and standardized processes in a way that minimizes the need for putting out fires, increases the preemption of failures, and makes way for anticipation of business needs. By having agreement at the business and user levels through the data governance process, IT's role in supporting the business will be made much simpler and more effective.

\section{Validation and Monitoring of System and Data}

Data definitions, business glossary terms, and data policies will inform and initiate system functionality change. As each new feature and system configuration is brought online, it needs to be verified it to make sure it aligns with the need, and to evaluate it against 
the larger system scope to identify any downstream impacts in a preemptive effort with a postimplementation handling plan. This cycle of user acceptance testing not only is critical to the stability and precision of deploying such new features, but also can aid in improving trust and user experience. A trusty but flexible test environment plays a key role in IT success and increased data quality.

Once features have been tested and implemented into the production environment, they must be monitored. If an issue is found and left untreated, it will erode data quality and reduce trust in the system. By combing through the ticketing system, IT staff can catch, address, and feed back to many other processes (e.g., project, systems management, and/or administrative) these trends for resolution and system restabilization.

The other method for monitoring the health of data is through a data profiling program that alerts users and business analysts to any data anomalies. A data profiling program creates a direct feedback loop to the Data Governance Committee about how data in each system comply with the data policies and definitions. In a data profiling program, the first step is the definition that is stored in a master data schema. Any anomalies discovered can be retroactively rectified and corrected, will help fulfill the goal of the data governance process, and, furthermore, will instill trust in the data.
The data dictionary obtained during the data governance meetings has served to provide the necessary definitions and value maps back to the transactional systems. These definitions have been stored in master data tables that provided the basis for data quality improvement. One means for this improvement is to build controls in the transactional system such that nonstandard values are prevented at the source. The other means for this improvement is that reports can reference these master data tables to pull information out in a way that aligns with definitions and values.

In our endeavor to improve data quality, we began with just a list of academic program offerings and their associated codes. In the SIS a combination of a program code, a degree code, and a curriculum code is what marks an academic program. If any of the codes within this code combination are not standard, information extracted on students and programs yields incorrect results and can negatively impact the SIS system automation. After devising this list of academic programs and inserting it into a table, the data architect built a custom database constraint that gave an error when users tried to save it in the system; this system prevented them, and other applications, from saving incorrect data. The same table was included in report queries to extract student and program information, which was particularly helpful with compliance reports.

\section{Customization and Automation of Reports}

UWS created a centralized data repository called the blended operational data store (BODS; see figure 13). This repository introduced the ability for staff to extract data from the SIS and insert it in the BODS where users can be assured of clean, accurate data. One of the first projects BODS was used for was a project to build an automated solution to keep Outlook current-term student distribution groups in synch with the SIS to facilitate timely communication with students. To build toward the future, additional attributes of an academic program, such as the classification of instructional programs (CIP) code and campus location (physical campus or online), have been added to the academic programs master data table to help answer other common questions about students and programs. As the data governance community matures, more master data tables that are similar will follow and the paradigm of building controls as well as reports from the same tables will grow stronger.

Another major reason of implementing a central data repository is that sometimes transactional system data are not in a format that meets the needs of user questions or are not in an environment that can handle the complexity of extracting those data as information. A separate database where transactional data have been transformed is required to achieve these goals. Building a central data repository requires understanding what constituents want to know about the 
Figure 13. Blended Operational Data Store Architecture
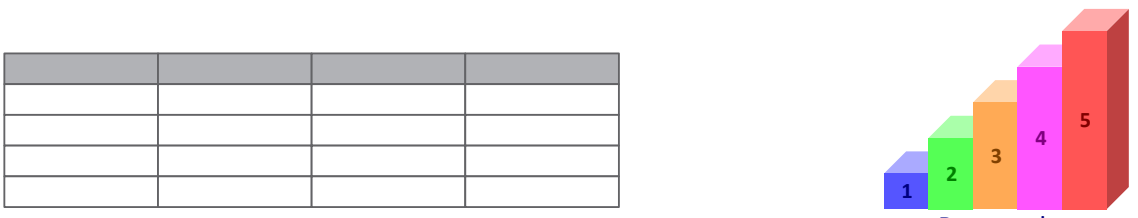

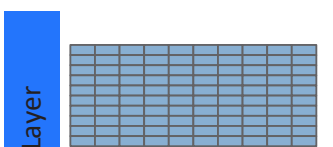

Marketing Site

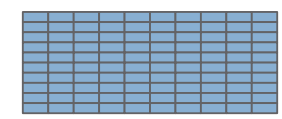

Clinic Site View

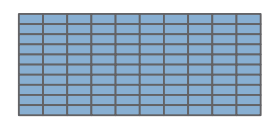

Assessment Site View
Bar graph

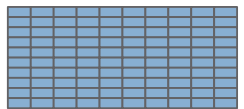

Registrar Site
View

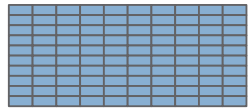

Financial Services

Financial Services
Site View

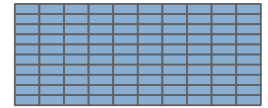

Admissions Site View

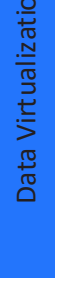

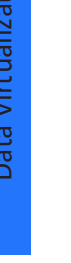
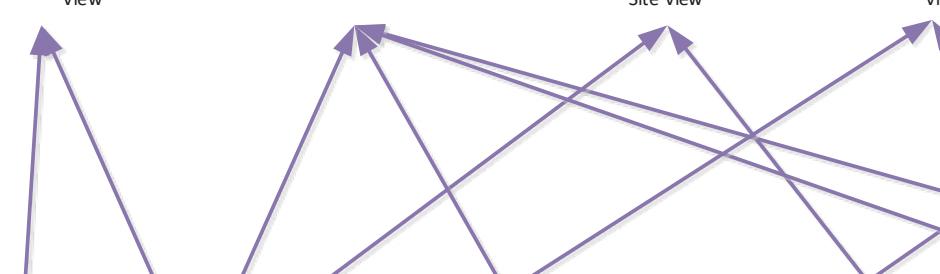

(1)
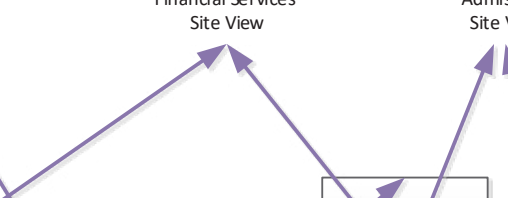

14
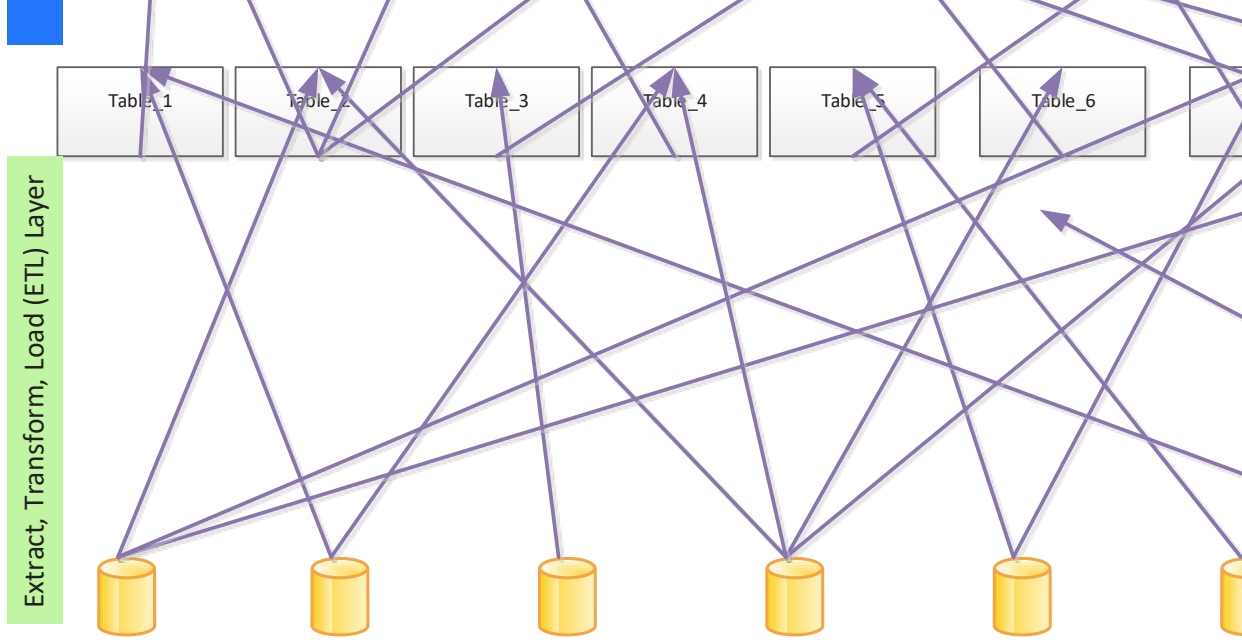

PowerCampus
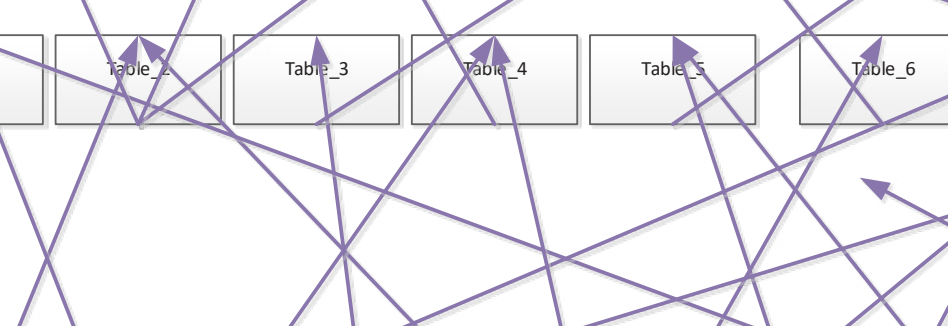

\section{(3)}
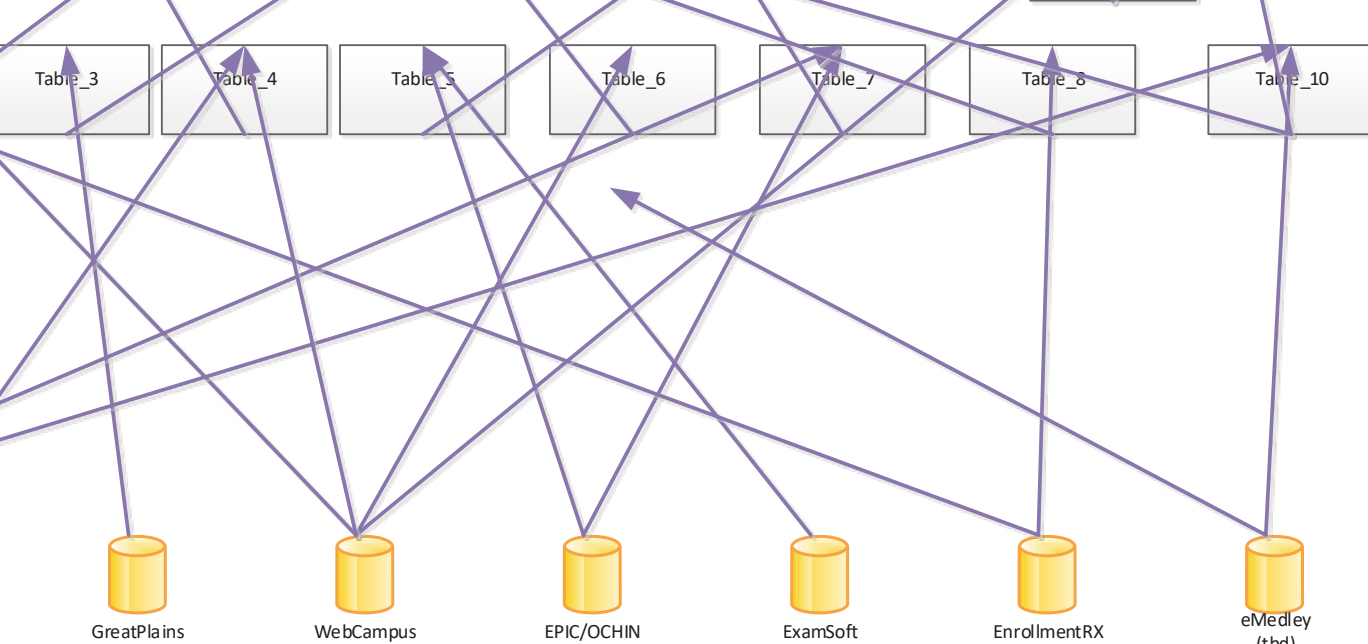

Note: The BODS architecture provides more details on the architecture to show the multiple back-end and front-end layers on the left and right sides of the diagram. The back-end layers are signified by the lower section of the diagram and include the extract, transform, and load layer and the data sources, and the front-facing layers include data virtualization and presentation. In the middle is the data model layer, which is where the data tables are stored and then flow upward for information to be presented.

university. The data architect designed information in the BODS schema in a way that increases completeness and reduces value redundancy, making the BODS the place from which staff can pull operational information and levels of data analysis and analytics.
As more variables and automated extract, transform, and load processes are added to the BODS, users can more quickly access common information needs with the understanding that all information seekers are working from the same data and definitions.

\section{CONCLUSION}

A 2017 Forbes magazine study found that $53 \%$ of companies have some form of big data analytics they rely on for change decisions with "reporting, dashboards, advanced visualization end-user 'self-service' 
and data warehousing [as] the top five technologies and initiatives strategic to business intelligence" (Columbus, 2017). Accreditation standards and compliance policies are driving the education sector in the same direction with demands for decisions based on calculated raw data. At the same time, information analysis and delivery technologies are growing exceedingly sophisticated, which enables quicker decisionmaking cycles that educational institutions can access once they better streamline administrative processes through cooperative automation. The university's experience with the NWCCU accreditation process has not only demonstrated this trend, but also has positioned UWS on the path of causing analytics to become an intrinsic aspect of running the institution.

There were many things that needed to happen at UWS in order for it to comply with accreditation standards. The main task for the institution was the need to conduct reliable IR. Other tasks included educating executives to prevent end users from working outside the systems, and holding those executives responsible for their actions and any vocal opposition to the changes. The data governance meetings became a platform for educating data stewards about their role and building trust in the systems; the Data Governance Committee leaders provided daily guidance to steer data steward activity to work within the systems. By virtue, trust was also being restored in the data themselves.
With the help of the IR specialist and a now accepting administration, university personnel went from not understanding the need for the position of IR specialist to heavily relying on the specialist's expertise. The IR specialist needed to be a change agent and to have the experience to know how to get the necessary resources to make big improvements to significantly increase data quality and availability in a reasonable time frame. There were many hurdles along the way but the largest was balancing the need for momentum to get all these major changes accomplished while not overwhelming an institution that was already dealing with change fatigue.

As for the status of UWS, there was a happy ending for the regional accreditation issues. In the Winter of 2018 the warnings were officially removed, the university was officially reaccredited, and UWS received commendations on how well they improved in many areas, including data management.

\section{REFERENCES}

Columbus, L. (2017, December 24). "53\% of Companies Are Adopting

Big Data Analytics." Forbes.

https://www.forbes.com/sites/

louiscolumbus/2017/12/24/53-ofcompanies-are-adopting-big-dataanalytics/\#471bdfde39a1 